\title{
Montane Meadows as a Microcosm for Predicting Global Change
}

\section{M. DEBINSKi DEPARTMENT OF ECOlOGy, EVOLUTION AND ORGANiSMAL Biology IOWA STATE UNIVERSITY ^ AMES}

\section{$\downarrow \quad$ INTRODUCTION}

The last decade has witnessed intensifying, abrupt global climate change. Despite this impact, we know little about when, what, and how changes occur. Most climate research is limited to studies of the abiotic environment, focusing on atmospheric composition and carbon fluxes. These studies fail to provide adequate indicators of climate changes and their impact on habitats and species. Recent and intensifying ecological changes have generated interest in (Root et al. 2003, Thomas et al. 2004), and the need for tools that can help to prepare for global climate shifts. Changes in ecological (biotic) communities are excellent indicators of climate shifts, providing models to predict changes over time. Montane meadows, defined here as persistently nonforested habitats in mountain ecosystems, make up a small percentage of terrestrial habitats, but they are likely to exhibit changes much more rapidly than most other areas. These meadows are arrayed along a hydrological gradient (from hydric to mesic to xeric) and inhabited by short-lived plants and highly mobile animal species that can exhibit quick changes in distribution patterns relative to environmental changes. Thus, they can provide an early warning system for other ecosystems across the globe. Currently, the extent and range of climatic changes that will occur in montane meadows are unknown.

This research focuses on collection and analysis of long-term data to determine how climate variability affects species distribution patterns in the Greater Yellowstone Ecosystem. Specifically, I have been quantifying landscape-level and ecological variability in montane meadow communities across three trophic levels (plants, butterflies, and birds). The central hypothesis for the proposed research is that montane meadows and their associated species are particularly sensitive to climate variations and thus can serve as early indicators of regional climate change. I have formulated this hypothesis based upon preliminary findings suggesting that montane meadows exhibit variations in patch size and classification as a response to interannual variability of climate and that there are related changes in species distribution patterns. The major objective of the research is to document temporal changes in species distribution patterns relative to habitat changes. I am examining how interannual climate variability affects the bird, and butterfly communities. I hypothesize that species will show interannual shifts in distribution along the hydrological gradient that are correlated with habitat changes. For example, butterfly species normally associated with xeric meadows may move into more mesic sites in a hotter, drier year.

1996-2001 were extremely dry years in the Greater Yellowstone region (Fig. 1), so this is an excellent time period during which to examine interannual variations in species distribution patterns. Abiotic change is easy to quantify using satellite data (Fig. 2), and because the landscape is predominantly xeric, I expected that changes would manifest themselves quickly. The taxa examined each provide unique indications of how changes in climate affect the biotic community. I expected that changes in distribution for birds and butterflies would be quick and show high interannual variability, yet also show strong correlation with annual climatic changes. I expected changes in the plant community to take 
longer to manifest themselves, but to exhibit lower interannual variance. Here I focus on an examination of the interannual variation in bird and butterfly species distribution patterns. The importance of collecting and analyzing these data lies in providing both an understanding of interannual baseline variations and creating a long-term data archive for species distributions.

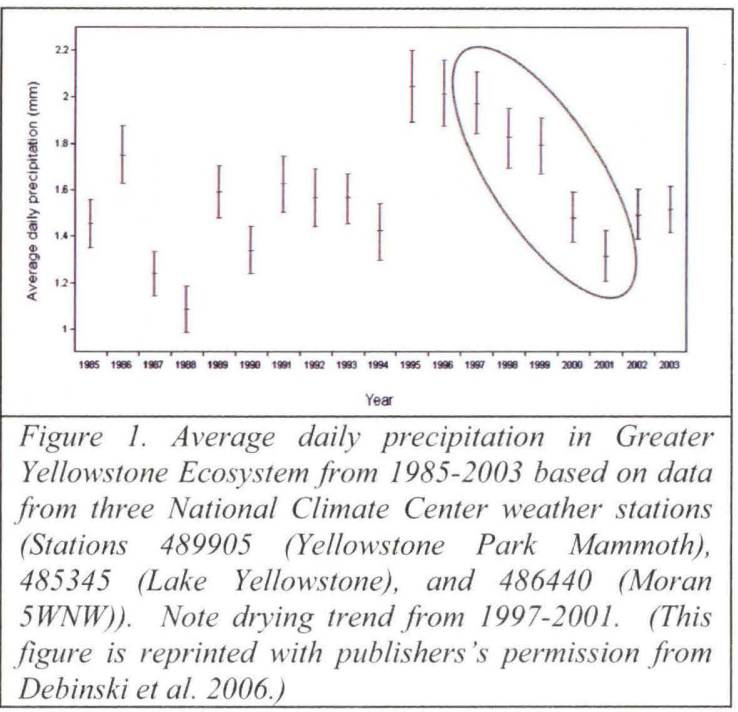

\section{$\uparrow \quad$ METHODS}

Our sampling sites were identified using classification of remotely sensed multispectral imagery to identify a moisture gradient in montane meadows. Six meadow types were defined, ranging from extremely hydric sedge and willow (M1) to extremely xeric (M6) sagebrush meadows (Debinski et al., 2000). We sampled extensively starting in 1997 in two regions of the ecosystem: the northern region (Gallatin study area) that includes the Gallatin National Forest and the northwestern portion of Yellowstone National Park; and the southern region (Teton study area) that includes Grand Teton National Park and the Bridger-Teton National Forest. We established 55 sampling sites: 30 sites were located in the Gallatin study area (5 of each of the six meadow types), and 25 sites were located in the Teton study area (5 of each meadow type except for M4 meadows, which are not found there). We focused our work on low elevation meadows (2000$2500 \mathrm{~m}$ ), to avoid introducing another environmental gradient (elevation) into our analysis. These sites were sampled annually for plants, butterflies, and birds until 2001, and surveys in the Teton region continued for birds and butterflies through 2005 .

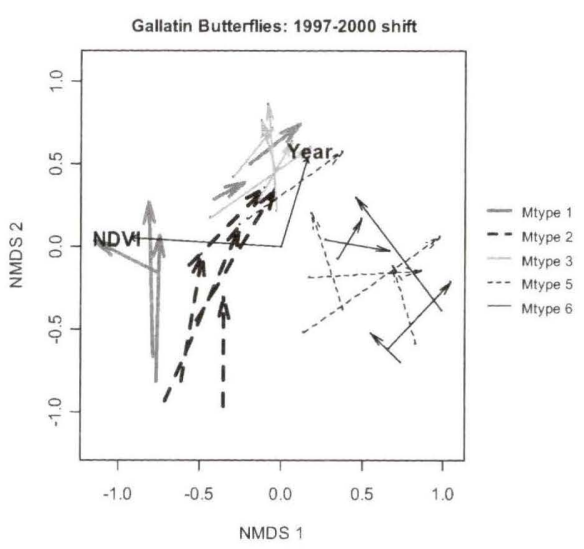

Figure 2. NMDS plot of Gallatin butterfly site-years for only 1997 and 2000 fitted with an NDVI and Year vector. Colored arrows point from 1997 to 2000 and the fitted Year vector summarizes the individual site-year shifts. The wet meadows (M-types 1, 2, and 3) appear to have a concurrent shift in the same direction, while the dry meadows (M-types 5 and 6) appear randomly oriented. (This figure is reprinted with publishers's permission from Debinski et al. 2006.)

Our research has shown that the meadow types do in fact have different ecological communities with respect to plants, butterflies, and birds (e.g., Debinski et al., 2002; Jakubauskas, 1998; Kindscher et al., 1998).

\section{Species Characterization in Sample Sites}

Bird data were collected from June to midJuly. Butterfly data were collected from mid-June to early-August. Birds and butterflies were surveyed two times during the field season at each of these sites. Birds (i.e., songbirds and woodpeckers) were surveyed between $0530-1030 \mathrm{hrs}$ using $15 \mathrm{~min}$. point counts in $50 \mathrm{~m}$ radius circular plots. Butterflies were surveyed between 0930-1630 hrs by two people netting for 20 minutes in $50 \times 50 \mathrm{~m}$ plots at each sampling site (e.g., Debinski and Brussard, 1992). Surveys were limited to times when temperature is above 70 degrees $\mathrm{F}$, wind is less than $16 \mathrm{~km} / \mathrm{hr}$, and the sun is not obscured by clouds. Butterfly sampling at each site was temporally spaced to cover the two major emergence periods during the summer.

\section{Community Analysis}

To detect trends in species composition over time, we used Non-metric multidimensional scaling (NMDS), an unconstrained ordination technique. NMDS can be used to ordinate sites in a two dimensional similarity space based on Bray-Curtis dissimilarity indices among sites. Each pair of points within the landscape represents a pair of replicates, and differences among times can be estimated by 
comparing the average temporal dissimilarity to the average replicates dissimilarity. Temporal trends can be described by the correlation of temporal dissimilarity with the length of time between samples. The closer sites are to each other in this plot, the more similar they are in species composition. The NMDS ordination is unconstrained in the sense that the spatial pattern of sites seen in the ordination plot is derived entirely from the structure of the species abundance data. Since each point in the ordination represents a site-year combination, among-year changes in species composition can be revealed. Environmental variables can then be overlayed onto the plot without disrupting the original ordination's integrity. Such variables can be represented by arrows or contour gradients, and the relative importance of each variable can be assessed. Specific species that have high loadings on one end of the gradient can also be identified, allowing for species-level assessments.

The rationale for comparing changes in species distribution across different taxonomic groups is that we expect each of the taxa to provide different, but important insights into how organisms with very different life history strategies respond to short-term variations in climate. We have developed a meadow habitat classification scheme and shown that plants, birds, and butterflies in this system show strong habitat affinities with specific meadow types (Kindscher et al., 1998, Jakubauskas et al., 1998, Debinski et al., 2002). Butterflies are capable of moving throughout the habitat matrix if conditions change, but they are also dependent upon the distribution of their host plants. Quantifying shortterm distributional changes in each of these taxa, and comparing changes across taxa will provide a window into understanding how communities might be expected to change in distribution relative to longer-term (e.g., decadal) changes.

\section{$\downarrow \quad$ Results}

Preliminary analysis of interannual meadow variation show some striking trends relative to climatic changes from a remotely sensed perspective (Debinski et al., 2000) and an ecological perspective. NMDS ordinations plot of butterfly, and bird communities have shown that similar M-types are closely grouped, indicating similar species compositions in those sites (Debinski et al., 2006). Because there was a significant drying trend in the region during 1997-2002, we decided to examine the data for temporal changes. There were no major changes over time for the bird data for either region or for the Teton butterfly data. However, Gallatin sites showed strong year effects for butterflies. Because year and short-term precipitation variables both showed significant correlations, we chose to examine these results graphically during a single time interval (1997-2000) when precipitation dropped drastically. We then connected only the 1997-2000 site-years with arrows (Fig. 2, Debinski et al., 2006). Nearly all of the mesic and hydric meadows (M1M3) show a trend towards a drier state, whereas there is no such trend in the xeric sites. The species strongly showing year effects were Phyciodes campestris, Speyeria atlantis hesperis, Pieris napi, Coenonympha haydenii, Boloria kriemheld and Oenius chryxus chryxus. Most of these species show strong habitat affinities with mesic meadows. To further support the argument that mesic to hydic species are most vulnerable, two wetland species were missing from the Teton sites in 2004 --Boloria frigga, a relatively common wetland species and Euphydryas gillettii, a rare wetland habitat associate. These species had been observed annually in these sites since 1997, were not observed in any of the Teton sites in 2004, but were present in 2005. These changes may just be the random variation observed within one year, but they reinforce the emerging story that hydric and mesic meadows may be much more sensitive to short-term variations in climate such as droughts. It will be important to monitor these species during the next few years.

\section{$\downarrow$ SUMMARY}

The Greater Yellowstone ecosystem is one of the largest "intact" ecosystems remaining in the temperate zones of the world (Keiter and Boyce, 1991), and thus provides an excellent opportunity to conduct natural experiments in a largely unmodified landscape. These long-term data and their analysis will be of critical significance given the projected warmer, drier conditions for montane environments in the Rocky Mountains. If smaller, more mesic to hydric meadows disappear, larger meadows will become more isolated and will serve as the only habitat source for demographic rescue effects (Brown and Kodric-Brown, 1977). It thus becomes important to monitor species distribution patterns over large spatial and temporal scales in order to unveil and predict some of these complex ecological interactions between climate variability, landscape, and biodiversity. 


\section{LITERATURE CITED}

Brown, J.H. and A. Kodric-Brown. 1977. Turnover rates in insular biogeography: Effect of immigration on extinction. Ecology 58:445449.

Debinski, D.M. and P.F. Brussard. 1992. Biological diversity assessment in Glacier National Park, Montana: I. Sampling design, in: Proceedings from the International Symposium on Ecological Indicators (D.H. McKenzie, D.E. Hyatt, and V.J. McDonald, editors). Elsevier Publishing. Essex, England. pp. 393-407

Debinski, D.M., M.E. Jakubauskas, and K. Kindscher. 2000. Montane meadows as indicators of environmental change. Environmental Monitoring and Assessment. 64:213-225.

Debinski, D.M., M.E. Jakubauskas, K. Kindscher, E.H. Saveraid, and M. Borgognone. 2002. Predicting meadow communities and species occurrences in the Greater Yellowstone Ecosystem, in: Predicting species occurrences: Issues of scale and accuracy (J.M. Scott, P. J. Heglund, M. Morrison, M. Raphael, J. Haufler, and B. Wall, editors). Island Press. Covello, CA. pp. 499-506.
Debinski, D.M., R.E. VanNimwegen and M.E. Jakubauskas. 2006. Quantifying relationships between bird and butterfly community shifts and environmental change. Ecological Applications 16;1:380393.

Jakubauskas, M.E., K. Kindscher, and D.M. Debinski. 1998. Multitemporal characterization and mapping of montane sagebrush communities using Indian IRS LISS-II imagery. Geocarto International. $13 ; 4.65-74$.

Keiter, R.B. and M.S. Boyce. 1991. The Greater Yellowstone Ecosystem: redefining America's wilderness heritage. Yale University Press. New Haven, Conn.

Kindscher, K., A. Frasier, M.E Jakubauskas, and D.M. Debinski. 1998. Identifying wetland meadows in Grand Teton National Park using remote sensing and average wetland values. Wetlands Ecology and Management. 5: 265-273

Root, T.L., J.T. Price, K. R. Hall, S.H. Schneider, C. Rosenzweig, and J.A. Pounds. 2003. Fingerprints of global warming on wild animals and plants. Nature 421:57-60.

Thomas, C. et al. 2004. Extinction risk from climate change. Nature 427, 145-148. 